\title{
The Economics of Publishing: The Consequences of Library and Research Copying
}

\author{
Colin Day \\ University of Michigan Press, University of Michigan, 839 Greene Street, 3297, P.O. Box 1104, \\ Ann Arbor, MI 48106. E-mail: colinday@umich.edu
}

\begin{abstract}
Copyright is a crucial property right. Two distinct, but intertwined, economic effects depend upon the ability to control use of that property right and to gain revenue from that use: the first is the incentive effect, and the second, the enabling effect. These two principles underpin the incentive for creating and the means for disseminating copyrighted works. Changes in copyright law can have far-reaching and large influences on the workings of these economic principles and the greater economy. Photocopying, interlibrary loan, and extensions of fair use all potentially lessen sales of copyrighted works, increasing the difficulty scholarly publishers have in underwriting and disseminating scholarly works. Broad interpretations of fair use may erode copyright protection and assuredly further erode the services of scholarly publishers that support the dissemination of academic writing.
\end{abstract}

The collapse of the Soviet Union and the Soviet-type economies has provided us with many lessons about the working of the economy. The basic conclusion that has been drawn by everyone from these failures is that the market is the best organizer of economic activity. We also learned much from that painful experience about the way economies work or do not work. We learned that a flourishing market must be embedded in a subtle and complex set of institutions to operate successfully. Central among those institutions are property rights. Markets do not work unless there are well-defined property rights, with mechanisms for assigning ownership of, for defending, and for buying and selling those property rights. Intellectual property rights and copyright are, of course, among those crucial property rights. By 1991, copyright industries in the United States accounted for $5.6 \%$ of GNP. They have been growing

(C) 1999 John Wiley \& Sons, Inc. Permission is hereby granted by the Publisher for this material only to reproduce, distribute, display, and transmit the articles in this "Perspectives" section for nonprofit purposes, provided that copies are distributed for noncommercial purposes only and not for resale or for systematic redistribution, and the author, source, and copyright notice are included on each copy. This permission is in addition to rights granted under Sections 107, 108, and other provisions of the U.S. Copyright Act. rapidly ever since. It is reasonable to estimate that the livelihoods of ten million individuals depend upon copyright in this country. The subject of fair use of copyrights is, therefore, not trivial. Changes in copyright law or practice can have far-reaching and large effects on the economy; it will not only be the profits of corporations that suffer, but the individuals whose jobs will be lost. I think we should always keep that issue in the foreground as we talk about copyright.

\section{Economic Effects}

Two different, albeit intertwined, economic effects depend upon the ability to control use of property and to gain revenue from that use. Both effects are relevant, whether we are dealing with intellectual property or with a more tangible product. The first is the incentive effect, and the second, the enabling effect. The incentive effect describes the fact that the prospect of revenue and profit encourages the maker to produce the good, to do it as efficiently as possible, to keep costs down, and to tailor the product to attract the most buyers. In the world of academic writing, it is the financial incentive that drives most textbook writers. People write for money. Without that incentive, most textbooks-and most other kinds of books - would not be written. The prospect of profit is predicated upon the ability to control access sufficiently to ensure that most readers buy the book, thus adding to the author's rewards. Most textbook writers will think about the market as they write, endeavoring to produce something that most teachers of courses will find useful. Thus, the effectiveness of the textbook also is guided by the wish to maximize revenue and profit. Of course, we all know of people who have written textbooks not for such monetary motives but because they believe that they have a particular and valuable pedagogic message to convey. This is even more true, of course, for the writer of the scholarly monograph. His or her economic motive is directed towards the tenure and promotion committees, not towards royalties. 
But here we come to the second effect-the enabling effect. It costs money to publish a book, and that money will be forthcoming, even from a nonprofit publisher, only if there is a prospect of sufficient revenue to recover the investment in the publishing process. In fact, there must be a good likelihood of full cost recovery. Thus, the availability and dissemination of a manuscript is made possible by the prospect of revenue. It is enabled by the assurance that the organization putting up the money for publication can sufficiently control access, and thus, can expect to sell copies to most of the potential readers. It is the copyright system that is the basis of that confidence; it is the copyright system that enables publication. Accordingly, even for the academic document written by an author purely for noneconomic motives, the copyright system is essential. The costs of actually publishing the work will be committed only if they are likely to be recovered and available to be used to finance the next author's work. It is a revolving fund concept. More importantly, as one who has tried and has watched others try more diligently than I, there is not enough foundation money, or any other sources of funding, to support even a tiny fraction of the academic works that deserve publication.

But, while primacy should be placed on the enabling effect, there also is a place in monograph publishing for the incentive effect. When a book is published in a cost-recovery mode, or even, as with the majority of books in the humanities, in somewhat less than cost-recovery mode, the incentive effect plays a role. We university presses do not select only those books that will make money; we are mainly guided by intrinsic and scholarly merit. The philosophy to which we aspire is nicely exemplified in a story from the early days of the University of Chicago Press. The first book to bear that distinguished imprint had after two years sold five copies. But the then director of the Press wrote enthusiastically to the university's president that it was "the kind of book for the Press to publish." We aspire to such an approach, but we also have to consider the enabling effect: can we foresee revenue adequate enough to cover the costs of publication or to bring the loss down to a manageable level? In much of scholarly-particularly humanities-publishing, that is the calculus: "can we absorb the loss?" But once we have committed to a book, the incentive effect kicks in. Can we make the work more appealing to a wider readership? How do we tightly control the costs of publication? How do we market the book to reach as many of its potential readers as is economically feasible? In other words, having committed to the book for noneconomic reasons, we now want to make it as widely read as possible and as economically viable as possible. This whole logic and the viability of academic publishing depend upon copyright. It is the definition of property that underpins the essential mechanism by which revenue is collected to cover the costs of publication.

\section{Effect of Photocopying, Interlibrary Loans, and Extensions of Fair Use}

Having established the economic centrality of copyright in enabling the scholarly publishing process, I now turn to the specific question that I was asked to address: what is the effect of photocopying, interlibrary loans, and extensions of fair use on scholarly publishing? The direct answer to that question is easy. These uses are already reducing the sales of scholarly publications because, at least in the humanities and social sciences, the economics of scholarly publishing are now painfully obvious. All devices that reduce sales make the task of disseminating the work of scholars in those fields more difficult. They weaken the enabling effect, and thus, prevent some deserving manuscripts from getting published. Consequently, the work those manuscripts contain is not added to the easily accessible sum total of human knowledge. The work is now arcane, buried somewhere, harder to track down, and will find fewer readers. That conclusion is the thrust of the argument that I will now develop in a little more detail. But I need to deal first with some of the questions that I am sure are in your minds.

One set of questions can be encapsulated as "but doesn't new technology solve all these problems?" This concept would really be the topic in full detail for another article. But the crucial point in the context of copyright is that publishing will still involve significant costs in an electronic environment, and those costs will still need to be recovered out of revenue flow whose foundation must be in welldefined property rights.

One other argument also might be in your minds. The argument is that this work can all be done by scholars themselves without the need for publishers or other kinds of intermediaries. Approximately 104,000 academic and scientific journals are published in the English language. University presses alone publish 5,000 new books each year. That figure represents about one in seven of all books published in the USA. I have excluded the Oxford and Cambridge Presses, which would increase that number to about 8,000 , taking the ratio to about one in five of all books published in this country. Shifting all of this activity to volunteer faculty labor is simply not realistic. Even if it were practical, however, the question remains whether it is sensible to divert the time of highly trained, extraordinarily talented people from the teaching and research, which only they can do, to the more mundane, less demanding tasks involved in publishing. I am sure that it is not sensible. Such proposals seem to me to sadly underestimate the value of the work of scholars.

In summary, I do not believe that these strategies would eliminate, or even substantially reduce, the need for a flow of revenue into the scholarly publishing process. That flow of revenue is essential to sustain the services that ensure effective, efficient, and selective dissemination of scholarly writings. Interlibrary loan, electronic reserve rooms, and broad extensions of the library and educational exemptions are all likely to reduce the sales of scholarly publications. 
Each of these activities provides the reader with an alternative to purchasing the relevant publication. Of course, in some instances, the user is not a potential purchaser. In other cases, such as for an out-of-print work, purchase is not a possibility. But the primary purpose-and primary effect- of these activities is to substitute for purchase. Their cumulative effect will be, and indeed has been, a reduction in the number of copies of every scholarly publication sold.

This conclusion does not depend on any sophisticated or complex economic reasoning. If a set of individuals, who are considering a product with a positive price, are now offered an option with a zero price, some will take the zero-price option. Sales of a product with a positive price will fall when a zero-price alternative is offered. Thus, if people, for whom the only way to obtain a document had been to buy the publication, are now offered free access through interlibrary loan, some will take that route and sales of the publication will be lower.

In most of these cases, however, we are not comparing exactly the same things. The purchase option brings with it a package of user services that is not identical to the package that comes with the zero-price option. A book, for example, is actually rather more convenient than a stack of photocopies. Therefore, even with such a pair of options, some people will continue to select the higher-price option, just as now some people still buy the hardcover even though the paperback is available. However, it does not take rocket science to conclude that the availability of the lower-priced option reduces the sales of the more-costly option.

As a result, the first conclusion that I want to put on the table is that the availability of means to access a document that are of low or zero cost to the actual reader will in nearly all cases have a negative effect on the sales of the document. Some publications will experience this effect more than others. The book that is a collection of papers undoubtedly has been badly affected by the availability of photocopying. A university press would not now accept many such books that would have been published twenty years ago.

The monograph, on the other hand, has been much less affected by photocopying, although I once was in a professor's office in a Japanese university and his room was lined with neatly bound photocopies of about 2,000 books. I was the publisher of only about 300 of them. But the ease with which interlibrary loans can be organized has certainly reduced both library and individual purchases of monographs.

\section{Effect of Sales Reduction on Scholarly Publishing}

What is the effect on scholarly publishing of this sales reduction? Answering this question requires that one myth be laid to rest. For the vast majority of scholarly books and journals, there is only the academic market, by which I mean libraries, scholars, and sometimes advanced students. A serious work on Dante does not have another substantial group of readers outside the academy. It is only within the academy that people know his work in sufficient detail to appreciate-even understand - the subtle and complex arguments, for example, about the use of language in The Inferno. No significant alternative market will cushion the sales lost from the academic community. I want to make this point especially clear, because it is often said that books and journals should be freely copyable for educational use. The clear presumption is that this is but a small part of the total demand for the publications, and therefore, should not significantly affect the likelihood of work getting published or diminish the revenue of the publisher. This could be true for a senior seminar on, say, "Classical Illusion and the Works of John Grisham." You could probably let all the students in that seminar get free copies of the texts by some means and John Grisham's publisher would not notice. But, for most academic publications, there is only the academic market and occasionally some text use. The academic market is the only, and the complete, market for most of the writings of scholars.

What does happen if sales are significantly reduced? Is there enough slack in the traditional markets for scholarly publications to accommodate a modest decrease in sales? The answer to that question, of course, varies with the publication. Some academic publications are highly profitable, or, at least, I have heard rumors of such. But, for most publications, in the humanities and social sciences, the economics are already exceedingly difficult. Most academic publishing houses balance the few largest selling titles against the many small selling ones, taking whatever surplus the former provide and committing it to the highly specialized books. Thus, even if a change affects only the more successful books, the effect will ripple through the whole structure as the books that would have been crosssubsidized from the successful titles are no longer supported. Consequently, the effect of activities that reduce the likelihood of students buying a particular book-such as photocopied coursepacks, digital reserve rooms, and so on-is to cut off one source of the funds that permit the more specialized works to be published at all.

\section{First-Copy Costs}

Understanding the consequences of reduction in sales requires a little attention to the economics of publishing. Most of the work of publishing occurs before we put ink to the first copy. These are what we call "first-copy" costs, which are actually incurred before the first copy is manufactured. For academic works, about $75 \%$ of all costs are incurred before the first copy is printed, and they are invariant with the quantity printed. They also are approximately media independent, that is, whether we put the text on paper or into an electronic file, most of these costs will be incurred. We recover our costs from the revenue obtained from selling copies of the publication. This is the enabling effect. If we expect to sell 1,000 copies of a book, we can basically look to recover one one-thousandth of these firstcopy costs from each copy sold. If we expect to sell only 500 , then we need to recover twice as much of the first-copy 
cost from each copy sold. Thus, as expected sales shrink, the amount of revenue we need from each sale rises. This is the primary reason why a popular novel is much cheaper than a scholarly work of comparable length. The fiction publisher is spreading its first-copy costs over 100,000 copies, the academic publisher over perhaps 750 copies, and often less. Of course, when you put it this way, the marvel is that the price differential is so small, perhaps $\$ 24.95$ for the novel and $\$ 39.50$ for the academic book.

There are many reasons for this result, but they would take us far afield from the theme of this article. One reason is, however, germane. University presses actually have been in the forefront of using new technology to reduce the first-copy costs. They are far in advance of trade publishers in the use of computers, and they are still pioneering new technologies in book production. They also have produced remarkable gains in staff productivity.

What has driven us to be so innovative, and so energetic, in seeking cost savings? The simple explanation: the sale of the books that we have committed to publishing has been shrinking steadily over the past two and a half decades. I came into publishing in 1976, and at that time, you could generally reckon to print and sell about 1,500 copies of a book. At that point, my colleagues already were reminiscing about the great days at the end of the 1960s: "you could sell 2,000 of anything," they would say. I do not have data on what the average is today, but there are a lot of books for which we sell 700. More importantly, I suspect that quite often we are kidding ourselves, and we will not sell even 700 copies of those books.

The pressure of reducing sales and somehow making the economics of this business work have been relentless for two decades or more. To a considerable degree, commercial publishers have abandoned the scholarly book. University presses produce scholarly works, despite increasing difficulty, because we believe that there is a need and a cultural value to such publishing that transcend the market-driven values. But no one has been shoveling money our way to ease the pain of diminishing sales. Indeed, while the economics of publishing has changed, we also generally have been facing reductions in university financial support. Consequently, we have had to energetically pursue and find cost savings. Because we have been seeking these economies and raising productivity for a long time, there is no slack left to be squeezed out of the system to accommodate the next shrinkage in sales volume. However, we continue to seek technical innovations that may provide economies. Onscreen copyediting is something that most of us do now, but it has not yet percolated through the entire business. We are not sure that it is saving money, but we are hopeful.

\section{A Sense of Crisis}

There are no easy solutions, however; no quick fixes, no major cost saving strategies. Unfortunately, we need major cost savings today. The modest productivity gains that we could probably continue to find, a couple of percent per annum-and that is pretty good by American industry standards-will not be enough. The arithmetic now requires that we find much larger cost savings than ever before. This brute fact of arithmetic gives me a real sense of crisis, and leaves me sure that a gradual gain in productivity is no longer enough. We are running into a wall.

Reduced sales of academic books with no financial relief lead inevitably to the withdrawal of the publisher from areas of academic publishing where sales amounts are below the tolerable threshold. Large swathes of the humanities and social sciences are likely to be harmed in this way. We have stopped publishing in some areas already, and we may abandon more. If you came to me with a significant work on Balzac or Tolstoy, I would have to seriously question whether we could publish it.

The academy has a complex and multifaceted interaction with copyright law. Cheap materials and simply obtained permissions are valuable, but so, too, is the availability of efficient and diverse channels for performing the functions of selection, editing, design, distribution, and marketing. The efficiencies to the whole university system that come from careful selection by a neutral agency are substantial. The largest cost by far in the whole process is not the buying and handling of materials. It is not what the librarians spend, and it is not what the publishers spend. It is actually the value of the time spent reading the materials at the end of that chain. Many of the benefits that help readers use that valuable and painfully scarce reading time to maximum advantage are provided by publishers, and providing those benefits costs money. It requires a revenue stream for support. Regardless of whoever actually manages or provides those benefits, they can continue only under a copyright regime similar to-although perhaps not identical to- - today's regime.

I believe that there is room for fine tuning and for some rebalancing of the different interests involved. But, a major erosion of copyright protection does assuredly bring with it a major erosion of the services that underpin the quality and dissemination of academic writing. 